\title{
Revalidation in the UK
}

\author{
Zosia Kmietowicz
}

Revalidation was first proposed by the General Medical Council in 1998 as a way to win back the trust of the British public after a series of medical scandals. The GMC, which regulates UK doctors, said it would ensure that all of the UK's 200000 doctors were up to date and fit to practise. For the first time every competent doctor in the UK would be issued with a licence to practise. And every five years they would be required to prove that they had kept up to date and continued to perform to required standards or lose their licence. ${ }^{1}$

\section{Why revalidation was needed}

In the past the GMC has taken a reactive rather then proactive approach to doctors' performance. It followed up complaints made against doctors but did not routinely check competence. Deficiencies in the way the GMC regulated doctors came to light in 1995 after concerns emerged about three doctors running the paediatric cardiac service at Bristol Royal Infirmary. ${ }^{2}$ The GMC began discussing ways of modernising its methods, although revalidation was not universally accepted at first.

Two high profile cases of professional incompetence probably helped to accelerate a move towards licensing doctors. In September 1998, Rodney Ledward, who had worked as a gynaecologist in Kent for many years, was struck off the medical register. ${ }^{3}$ He had been known to be delivering care that was below acceptable standards for some years but had been allowed to continue practising. In the same month Harold Shipman was arrested, and his catalogue of killings that stretched back at least 23 years began to unfold.

\section{Initial plans}

By February 1999 the GMC voted to introduce revalidation. In June 2000 it published a consultation paper in which it set out the objectives of revalidation and explained how the scheme would run. Doctors would be required to maintain a folder which contained information about how they practised. This could include certificates of postgraduate training, results of significant event analysis, audits, patient satisfaction surveys, complaints, lessons learnt, and results from clinical governance visits.

The folders would be reviewed every year at a doctor's annual appraisal, which has been recently introduced into the NHS for both hospital doctors and general practitioners. In addition, every five years doctors would go before a revalidation panel made up of doctors and lay people. This panel would decide whether a doctor was fit to practise based on the contents of the folder and standards of practice set out by the GMC and the royal colleges. Doctors who could not be revalidated would be referred to the GMC, which would decide whether to invoke fitness to practise procedures, to suspend the doctor, or to issue a licence with conditions attached.

The proposals on revalidation were launched at a time when clinical governance was taking hold in the NHS, and the paper acknowledged that this would provide added protection for patients against poor performing doctors. But it also stressed that neither revalidation nor clinical governance alone was able to identify incompetent doctors at the earliest opportunity. In December 2002, the Medical Act 1983 was amended and revalidation (as defined in the GMC's consultation paper) was enshrined in law.

\section{Modification}

However, by April 2003 the GMC had changed its plans. The proposal to evaluate doctors by revalidation panels was dropped. Instead, revalidation would be based on doctors' annual appraisal forms. Provided that they could show they had had five consecutive appraisals doctors would be given a licence to practise before the end of 2004. Then from April 2005 doctors would be required to prove they were fit to renew their licence through revalidation every five years.

The terms of revalidation had also altered. Doctors who worked in a quality assured environment where clinical governance operated and who had annual appraisals could base their application for revalidation on the results of their appraisals. Those doctors who worked outside the NHS would have to collect documents that reflected their practice similar to those described in the consultation paper. The GMC told doctors that they would be revalidated provided there was no evidence that they were not fit to practise.

During the Shipman inquiry, Dame Janet Smith raised concerns that the GMC was equating appraisal with fitness to practise. ${ }^{4}$ However, appraisals were not set up to make judgments about doctors' competence but as an opportunity for a doctor to discuss issues of practice and plan improvements and career developments. Her concerns led the GMC to alter its plans for revalidation again. As well as providing evidence of appraisal, doctors would be required to produce a clinical governance certificate signed by a senior officer from the organisation that employed them.

In effect, said Dame Janet in her report, the onus of checking a doctor's fitness had passed from the GMC to the appraiser and clinical governance systems within the NHS. Neither of these systems was fully established. They varied in quality across the NHS, and Dame Janet was doubtful that in its current form revalidation would offer any more protection to patients than that already available. ${ }^{5}$ She was also concerned that the public was being duped by the GMC's insistence that revalidation tested doctors' fitness to practise. "The public has been told that revalidation is rather like an MOT test for doctors ... It is nothing of the sort," she said.

Revalidation was due to be launched this April, but the publication of the fifth report of the Shipman inquiry ${ }^{5}$ forced the GMC to shelve its plans. There were suggestions that new measures may need to be introduced to protect both patients and doctors. ${ }^{4}$ A high level review of the GMC's proposals is now being conducted by the chief medical officer for England, Sir Liam Donaldson.

Zosia Kmietowicz freelance journalist, London N16 7QJ zosia@blueyonder.co.uk

\section{Competing interests: None declared.}

1 Esmail A. Failure to act on good intentions. BMJ 2005;330:1144-7.

2 Dyer O. Hospital banned from doing neonatal operations. BMJ 1995;310:960.

3 Dyer C. Gynaecologist showed "lack of care and judgment." BMJ 1998;317:965.

4 Shipman Inquiry. Safeguarding patients: lessons from the past-proposals for the future. www.the-shipman-inquiry.org.uk/fifthreport.asp (accessed 19 Apr 2005).

5 Department of Health. Revalidation to be reviewed. Press release 17 April, 2004 (Series No 2004/0453). 